Article

\title{
Impact of the Altitudinal Gradients of Precipitation on the Radar QPE Bias in the French Alps
}

\author{
Dominique Faure $^{1, *}$, Guy Delrieu ${ }^{2}$ and Nicolas Gaussiat ${ }^{1}$ \\ 1 Météo-France, Centre de Météorologie Radar, 31100 Toulouse, France; nicolas.gaussiat@meteo.fr \\ 2 Institute for Geosciences and Environmental research (IGE, UMR5001), University Grenoble \\ Alpes-CNRS-IRD Grenoble-INP, 38000 Grenoble, France; guy.delrieu@univ-grenoble-alpes.fr \\ * Correspondence: dominique.faure@meteo.fr; Tel.: +33-561-079-515
}

Received: 8 April 2019; Accepted: 29 May 2019; Published: 3 June 2019

\begin{abstract}
In the French Alps the quality of the radar Quantitative Precipitation Estimation (QPE) is limited by the topography and the vertical structure of precipitation. A previous study realized in all the French Alps, has shown a general bias between values of the national radar QPE composite and the rain gauge measurements: a radar QPE over-estimation at low altitude (+20\% at $200 \mathrm{~m}$ a.s.l.), and an increasing underestimation at high altitudes (until $-40 \%$ at $2100 \mathrm{~m}$ a.s.l.). This trend has been linked to altitudinal gradients of precipitation observed at ground level. This paper analyzes relative altitudinal gradients of precipitation estimated with rain gauges measurements in 2016 for three massifs around Grenoble, and for different temporal accumulations (yearly, seasonal, monthly, daily). Comparisons of radar and rain gauge accumulations confirm the bias previously observed. The parts of the current radar data processing affecting the bias value are pointed out. The analysis shows a coherency between the relative gradient values estimated at the different temporal accumulations. Vertical profiles of precipitation detected by a research radar installed at the bottom of the valley also show how the wide horizontal variability of precipitation inside the valley can affect the gradient estimation.
\end{abstract}

Keywords: altitudinal; gradient; precipitation; Alps; mountain; radar; quantitative precipitation estimation; QPE

\section{Introduction}

In the French Alps, the quality of radar Quantitative Precipitation Estimation (QPE) provided by the French weather radar network is limited by difficulties of measurement, which increase the impact of well-known sources of error in radar data processing. Large areas are exposed to strong ground clutter and to important partial or total radar beam blockage by the relief. The distance to the radars and the altitude of measurement may be important, which expose to non-uniform beam filling effects, the proximity to $0^{\circ} \mathrm{C}$ isotherm altitude and the impact of the melting layer (solid and liquid phases in the radar sampling volume affecting the precipitation estimation, bright band, signal attenuation). For radars in altitude closer to areas of interest, measurements at low elevation angles can be affected by very important attenuation (particularly for $\mathrm{X}$ band radars) when the radar is situated within the melting layer, which is common in winter season. One can also observe that the distant $C$ band radars of the network and the X band radars installed within the mountain chain between $1740 \mathrm{~m}$ and $2580 \mathrm{~m}$ of altitude, scan the atmosphere above the mountain range and cannot detect precipitation into the valleys. This indicates that the radar data processing has no information on the evolution of precipitation in the valleys.

At Météo-France, the volume scan of each radar is processed every $5 \mathrm{~min}$ to estimate a single radar QPE map (by taking into account a great number of sources of error), and the QPE maps of all the radars are finally merged into a national radar QPE composite named PANTHERE (Projet Aramis Nouvelles 
Technologies en Hydrométéorologie Extension et REnouvellement). In 2017 Météo-France performed an extensive study on the operational products of the entire year 2016 to determine an updated estimate of the operational radar QPE quality in all the French Alps [1]. This study detailed the quality of the PANTHERE composite for each mountain massif and great valley, including all the areas defined to be of major interest by the French "Direction générale de la prévention des risques" (DGPR). In addition to several local reductions in quality due to different sources of error, this study has shown a general bias between values of this national radar QPE composite and the measurements of 430 rain gauges: a radar QPE over-estimation at low altitude ( $+20 \%$ at $200 \mathrm{~m}$ a.s.l.) and an increasing underestimation at high altitude (until $-40 \%$ at $2100 \mathrm{~m}$ a.s.l.) (Figure $1 \mathrm{a}, \mathrm{c}$ ). A detailed analysis confirmed this tendency for each massif and great valley, and the main factor identified to explain this observation was the altitude of the rain gauges. This trend has been related to altitudinal gradients of precipitation commonly observed at ground level in the French Alps, and not taken into account by the current radar data processing. In order to verify this relation, a simple uniform linear correction was performed, only function of the rain gauges altitudes. This correction produced a great improvement of the radar QPE, both for the bias and the correlation between radar and rain gauges annual precipitation (Figure 1b,d).

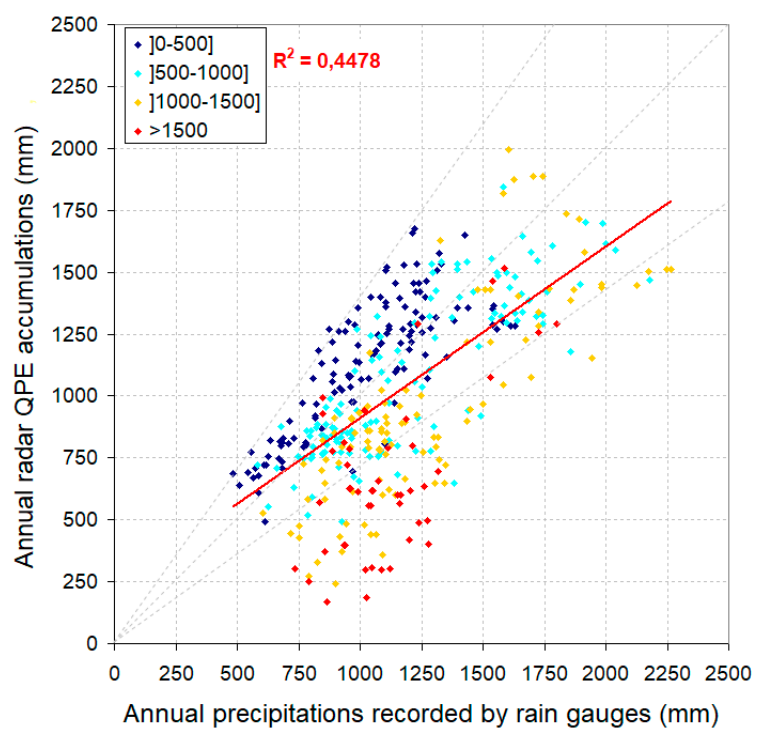

(a)

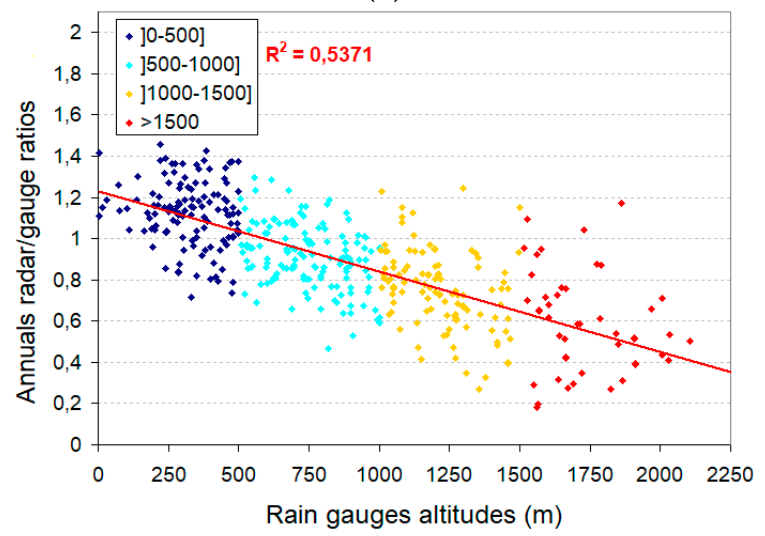

(c)

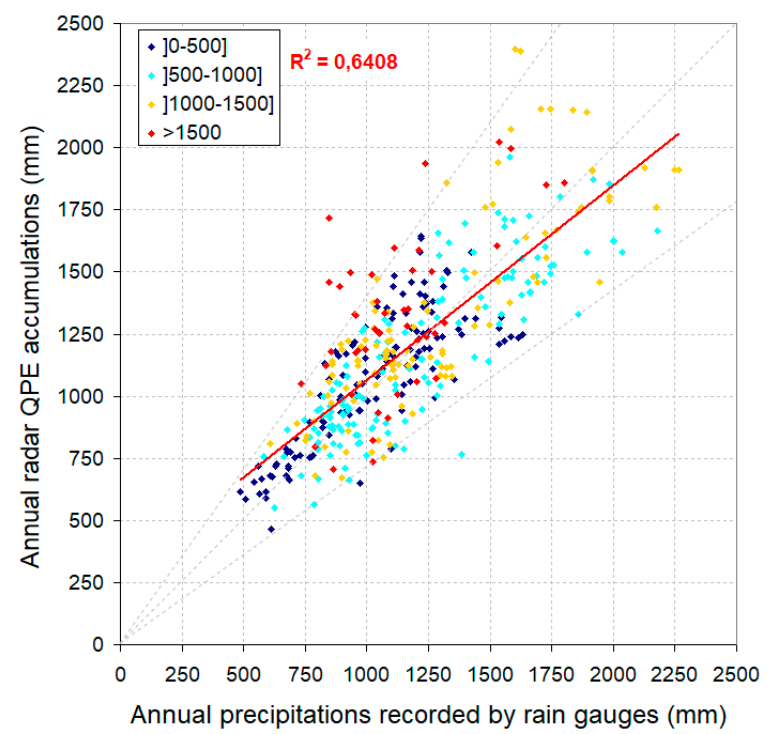

(b)

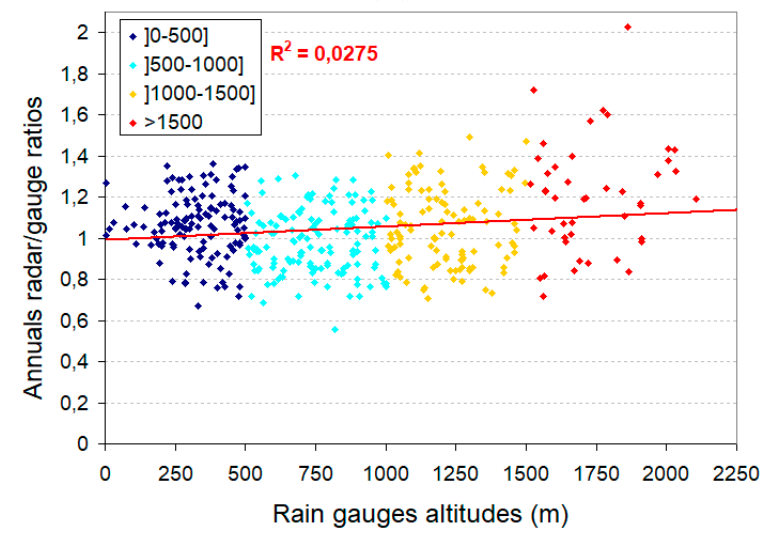

(d)

Figure 1. Comparison between annual radar quantitative precipitation sstimation (QPE) and rain gauge measurements, for 430 rain gauges in the French Alps in 2016 (colors function of the rain gauges altitude in $\mathrm{m}$ ): (a) scatter plot of radar QPE vs rain gauge data; (b) the same after the linear correction; (c) radar QPE bias as a function of rain gauges altitudes, for operational data; and (d) the same after the linear correction. 
The evolution of precipitation with altitude in the Alps has been studied by a number of researchers, and in the French Alps several analysis of precipitation, or reanalysis of climate data, have been carried out on trends depending on altitude as in [2-4]. Durand et al. [5] present meteorological trends for precipitation, showing that the climate of the French Alps is mainly determined by a northwesterly atmospheric flow, and that the vertical rainfall gradients estimated on annual precipitation in $\mathrm{mm}$ show a latitudinal dependence: within the 1958-2002 period, from north to south the mean annual vertical rainfall gradient vary from 294 to 195, 172, and $178 \mathrm{~mm}(1000 \mathrm{~m})^{-1}$. In the region located between the conurbations of Lyon and Grenoble, in the foothills of the Alps, the impact of relief on precipitation has been studied in two $\mathrm{PhD}$ theses using data from a one-dimensional dense rain gauges network of $100 \mathrm{~km}$ long crossing the Bas-Dauphiné, Chartreuse and Belledonne massifs [6-8]. These studies evidenced a clear influence of the relief depending on the weather regime, and Desurosne in [7], estimated that $83 \%$ of precipitation events correspond to an increase in precipitation with altitude within the 1987-1990 period. The influence of topography is also taken into account to estimate the AURELHY (Analyse utilisant le relief pour l'hydrométéorologie) spatial normals over the French territory $[9,10]$, which are spatial climate normals (including precipitation) routinely estimated by Météo-France for different time scales. For operational needs concerning the snowpack estimation, climatological vertical profiles of precipitation have been defined for 23 massifs in the French Alps assumed to be homogeneous for meteorological and climate conditions. These profiles are commonly used in the SAFRAN (Système d'Analyse Fournissant des Renseignements Adaptés à la Nivologie) analysis system $[2,11]$, initially designed for avalanche hazard forecasting. The SAFRAN profiles are non-linear, showing a decrease of the gradients with altitude between $300 \mathrm{~m}$ and $1800 \mathrm{~m}$ a.s.l. Observation of a reduction or inversion of the gradient values at high altitude is common in the French Alps, and this evolution is also mentioned in Switzerland for the gradients in the valleys and on the slopes [12,13].

Nevertheless, altitudinal gradients of precipitation are not easy to estimate and use for short time scales, as these gradients vary in time and space, and depend on several factors (orographic effects, slope orientation, seasons, weather, and precipitation regimes). Moreover, some issues affect the measurement of precipitation in altitude: number and sitting of gauges, lack of reliable and accurate snowfall measurements, and the need for analysis or spatial interpolation methods $[3,14,15]$. Finally, many other phenomena impact the precipitation at short time scales, which can make it difficult to estimate altitudinal gradients of precipitation.

In order to better investigate the relation between these altitudinal gradients and the bias observed between radar QPEs and rain gauge measurements, a more detailed analysis of the 2016 dataset has been carried out over a limited area around the Grenoble conurbation with a subset of 23 daily rain gauges. This paper focuses on the altitudinal gradients of precipitation observed at ground level by these rain gauges for different temporal accumulations (yearly, three months periods, monthly, daily) and for three neighboring massifs. Three main questions were posed:

1. How these altitudinal gradients at ground level could explain the radar QPE bias observed in 2016?

2. Can the altitudinal gradients observed in annual data be observed at shorter time scales, despite all the factors impacting their estimation?

3. Are the altitudinal gradients of precipitation observed at ground level related to the vertical profiles detected by radar, which could have an interest for the radar QPE bias correction?

\section{Experiments}

\subsection{Grenoble Site and Instrumentation}

Grenoble, the greatest French Alps conurbation $(\approx 500,000$ inhabitants), is situated at the confluence of the Isère and Drac rivers, and surrounded by three mountain massifs (Vercors, Chartreuse, Belledonne) rising up to $2000 \mathrm{~m}$ and $3000 \mathrm{~m}$ high (Figure 2). The region is located on the northwest side of the 
Alps, facing the main atmospheric flow on the country, and receives important annual precipitation particularly in Chartreuse. Chartreuse and Vercors are two massifs of the Alpine foothills (Prealps) while Belledonne is a more internal massif.

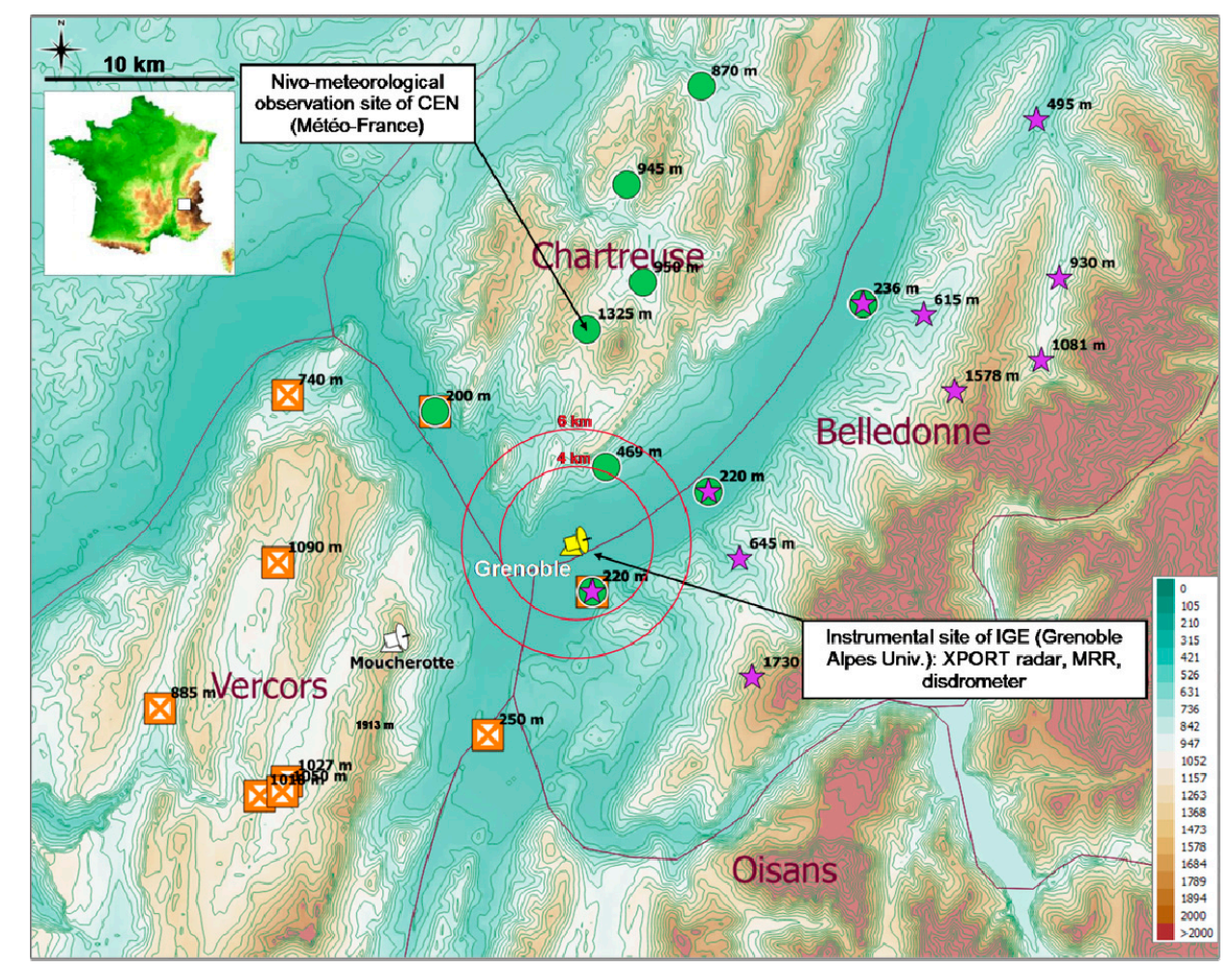

Figure 2. Relief $(\mathrm{m})$ and instrumentation. Brown lines = massifs limits. Rain gauges distribution: Chartreuse (green rounds), Vercors (orange squares), and Belledonne (purple stars).

In this study, 23 daily rain gauges were used, located both at the bottom of the valleys (around $220 \mathrm{~m}$ a.s.1.), on the slopes, and upper part of the three massifs (up to $1730 \mathrm{~m}$ a.s.1.). A radar of the national operational network (Moucherotte polarimetric X-band radar, $1910 \mathrm{~m}$ a.s.l.) is located inside the studied area at the top of the Vercors massif, which guarantees a good radar coverage of the area. The research instrumental site installed by IGE in the Grenoble Alpes University campus at $227 \mathrm{~m}$ a.s.l. [16] completes the observation of the atmosphere inside the valley, in particular with volume scans of the polarimetric X-band research radar named XPORT. One can also mention on the Chartreuse border (1325 $\mathrm{m}$ a.s.l.), the snow and meteorological observation site of the French Snow Research Center (CEN) of Météo-France.

\subsection{Data}

Monthly precipitation records were found to be similar for the three massifs, with a little more precipitation in Chartreuse. No precipitation was recorded in the area in December, 2016, except few millimeters in Vercors on one day. Therefore, this month is not represented in the results.

The 23 rain gauges constitute a dense and reliable local permanent network, constituted from several institutional networks:

- Data for 22 rain gauges was provided by the Météo-France national databases, which include sensors from partner's networks: Météo-France, EDF (Electricité de France), DGPR, and local authorities. All the data benefit from a routinely non-real time validation procedure with human expertise. These gauges provide data at the daily time step, and half of them also provide hourly data. 
- One rain gauge location corresponds to two hourly rain gauges of the CEN observation site in Chartreuse, with a distance of few meters between the two stations. The hourly measurements of these two rain gauges (correlation coefficient $=0.96$ ), not yet validated, were critically analyzed in this study. The most reliable gauge was selected, but for some periods with missing values, measurements from the other gauge were used in order to provide a unique continuous series.

Radar QPEs were provided by the operational PANTHERE composite product ( $5 \mathrm{~min}-1 \mathrm{~km}{ }^{2}$ resolution), which merge the single radar QPEs of 29 radars in 2016. In the area concerned by this study, the main contribution to the QPE composite values was provided by the Moucherotte radar (half-power beamwidth equal to 1.28 degree, bin resolution equal to $240 \mathrm{~m}$ ). Furthermore, several polarimetric C-band radars away located outside the area in Figure 2 also contributed (half-power beamwidth equal to 1.1 degree, bin resolution equal to $240 \mathrm{~m}$ ). The radar data processing, described in [17], performs the correction of several sources of errors in the precipitation estimation for each radar, including the utilization of a vertical profile of reflectivity (VPR) to transform the vertically integrated radar reflectivity measurements aloft in precipitation at the altitude of a reference level. Every five minutes, for each radar, a VPR model defined by four parameters is fitted using the volume data of the radar (Figure 3). This VPR varies in time but is supposed to be constant horizontally for all the single radar coverage. An important point is that this fitted model is defined to be constant (i.e., vertical) below the melting layer or below the radar altitude. In a final processing step, each single radar QPE is calibrated by rain gauge measurements with a mean hourly correction factor applied uniformly for all the radar coverage. The merging process elaborating the PANTHERE composite from all the single radar QPEs does not include any spatial adjustment, or any local bias correction, which could locally reduce the bias with the rain gauge measurements at ground level. In this study, for each rain gauge location the corresponding $5 \mathrm{~min}$ PANTHERE QPE value (in $\mathrm{mm}$ ) was extracted, and cumulated for different accumulation times. The all year 2016 represents more than 105,000 composites (288 a day). The number of missing values does not exceed 2 composites a day, and the number of days with such missing data does not exceed 12 days for the whole year 2016.

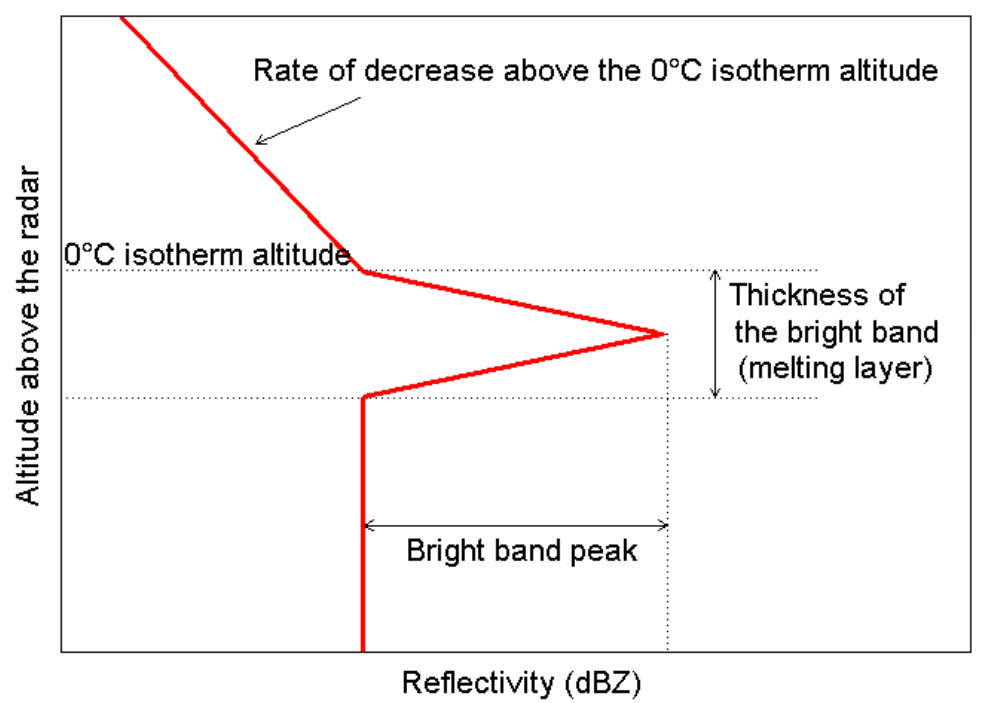

Figure 3. Example of vertical profile or reflectivity model defined above the radar altitude with four parameters.

The XPORT research radar operation was not continuous but alert-based, and IGE recorded a great number of precipitation events in Grenoble. In this study, data from 2016 and 2017 was used.

The $0{ }^{\circ} \mathrm{C}$ isotherm altitudes have been estimated by the analysis of the AROME (Applications de la Recherche à l'Opérationnel à Méso-Echelle) numerical weather prediction (NWP) model. The AROME version used has a $0.025^{\circ}$ horizontal resolution (about $2.5 \mathrm{~km}$ at Grenoble), and 60 non-equidistant 
vertical levels. The vertical resolution varies with the altitude above the ground, from $17 \mathrm{~m}$ near the ground to a few hundred meters. The $0{ }^{\circ} \mathrm{C}$ isotherm altitude has been estimated by interpolation between two vertical levels for the radar location.

\subsection{Methods}

Three subsets of rain gauges have been allocated to the three massifs, in order to estimate altitudinal gradients of precipitation at ground level for each massif, ideally on the slopes around Grenoble. These rain gauges are located on the north-western side of the Belledonne massif, the south side and the center of the Chartreuse massif, and in the north part of the Vercors massif. Four rain gauges at the bottom of the valleys have been allocated to several subsets, each valley separating two massifs. All the available rain gauges have been used for two reasons: (1) it would be difficult to justify rain gauge rejections (cf. Section 4); and (2) this allows the use of 9 or 10 rain gauges by massif.

For each subset, the rain gauge measurements have been cumulated for different temporal scales (yearly, seasonal, monthly, daily), the seasons being defined by the following triplets of months: (D) JF, MAM, JJA, and SON. In order to correctly estimate altitudinal gradients of precipitation, it is necessary to have exactly the same measurement periods for all rain gauges of the same subset, and then to eliminate a day for each missing value. Consequently, the number of daily values cumulated at each time scale is not exactly the same for all the massifs. One rain gauge representative of mid-altitude in Belledonne (615 $\mathrm{m}$ a.s.l.) was out of order in November. Therefore, the results were estimated with 10 rain gauges in order to have better annual results, but also with 9 rain gauges in order to have significant results in November and for the SON season. One rain gauge in Vercors (1018 $\mathrm{m}$ a.s.l.) was also out of order from 14 to 31 October, which eliminates 18 days for this month. The radar data used in the comparisons strictly corresponds to each restricted selection.

In this study, we assumed the altitudinal gradient constant with altitude for each massif, i.e., between $200 \mathrm{~m}$ and $1090 \mathrm{~m}$ a.s.l. for Vercors, $200 \mathrm{~m}$ and $1325 \mathrm{~m}$ a.s.l. for Chartreuse, $200 \mathrm{~m}$ and $1730 \mathrm{~m}$ a.s.l. for Belledonne. This simplifying assumption is discussed in Section 4. For each temporal accumulation and each massif, mean altitudinal gradients of precipitation have been estimated by simple linear regression (ordinary least-squares method) between rain gauge precipitation (dependent variable) and altitude of the gauges, as in $[3,14,18]$. These gradient values have also been normalized in relative gradients, as in $[4,17,19]$ in order to compare gradient values independent of the precipitation amount (see Section 3.2.1). One can observe that when the correlation coefficient $R$ tends towards zero, the gradient estimate also tends towards zero. So the gradient estimates with low correlation between precipitation and altitude have no signification other than "no gradient observed".

If we assume that the pair of two variables follows a bivariate normal distribution, it is theoretically possible to test if $\mathrm{R}$ is not significantly different from zero by testing this null hypothesis $\mathrm{H} 0$. The $t$ value estimated by the following equation, is supposed to follow a Student's t-distribution with n-2 degrees of freedom, with $\mathrm{n}$ the number of rain gauges of the subset:

$$
\mathrm{t}=\mathrm{R}\left[(\mathrm{n}-2) /\left(1-\mathrm{R}^{2}\right)\right]^{0.5}
$$

For 10 rain gauges, if $\mathrm{H} 0$ is true and for a significance level of $5 \%$, if $\mathrm{R}^{2}$ is inferior to 0.4 the null hypothesis should not be rejected. For 9 rain gauges, in the same conditions if $R^{2}$ is smaller than 0.44 the $\mathrm{H} 0$ hypothesis should not be rejected. It is also possible for each $\mathrm{R}$ value to estimate a $p$-value to test the null hypothesis that $\mathrm{R}$ is equal to zero. A low $p$-value ( $<0.05$ for example) indicates that the null hypothesis can be rejected with few risk of error. Obviously, the choice of rejection depends on the significance level chosen, and the relevance of this parametric test is conditioned by the assumption on the variables distribution. The $p$-values are presented only for the comparison of the annual accumulation of precipitation as a function of altitude, in order to highlight the difference between rain gauges measurements and radar QPEs. 
In the daily analysis, for all the three massifs the gradient estimates with $\mathrm{R}^{2}$ value below 0.25 were considered as non-significant gradients. Other non-significant gradient estimates were defined in the case of weak precipitation on a massif, defined by a mean of the daily values for the subset of gauges below $1 \mathrm{~mm} /$ day, and a maximum value for the subset below $3 \mathrm{~mm} /$ day (non-significant precipitation).

XPORT measurements have been used in this study only at high elevation angle $\left(25^{\circ}\right)$, because measurements at lower elevations $\left(3.5^{\circ}, 7.5^{\circ}, 15^{\circ}\right)$ were affected by ground clutter and radar beam blockage. For the $25^{\circ}$ elevation angle, the radar beam axis reaches $2000 \mathrm{~m}$ a.s.l. at only $4.2 \mathrm{~km}$ from the radar, and $2800 \mathrm{~m}$ a.s.l. at $6 \mathrm{~km}$ (red circles in Figure 2). Then, these radar measurements cover only a limited horizontal domain at low altitude. These measurements have been used to estimate mean apparent vertical profiles of precipitation (using the $Z=200 \mathrm{R}^{1.6}$ relationship), without taking into account measurements less than $1.3 \mathrm{~km}$ away from the radar (measurements being unreliable at short distances). Due to the high elevation angle used and of the short distances from the radar, these apparent vertical profiles are only slightly influenced by the geometry of the radar beam (small size of the resolution volume, little impact of non-uniform beam filling). These apparent vertical profiles integrate the horizontal variability only over a few kilometers.

\section{Results}

\subsection{Annual Precipitation and Radar QPE Bias for Each Massif}

In Figure 4, for each massif surrounding Grenoble, the 2016 annual amounts of precipitation measured by each subset of rain gauges are compared to the corresponding radar QPE values. For 13 rain gauges, which are climatological stations (among the 23 rain gauges), we observed that the annual amounts of precipitation in 2016 were close to their annual normals estimated by the AURELHY method between 1981 and 2010: the mean difference was equal to $-5.8 \%$.

For the three massifs, the rain gauge annual accumulations show an increasing trend with the altitude of the gauges ( $p$-values equal to $0.0024,0.0717$, and 0.0230 ). On the contrary, the annual radar QPEs appear independent of the altitude considered ( $p$-values equal to $0.3169,0.7512$, and 0.3146 ). This may be explained by the radar data processing used for each single radar, which does not take into account the relief or any altitudinal gradient of precipitation. On the contrary, this processing tends to estimate precipitation on a reference level with a constant altitude for all radar coverage, this level being defined in two stages:

- First by the VPR processing, which estimates precipitation on a reference level corresponding to the altitude of the radar or the altitude of the bottom of the melting layer, by using a VPR model as defined Figure 3. Indeed, this VPR model is always defined constant below the maximal value of these two altitudes, and this model does not describe the vertical evolution of the radar reflectivity below these altitudes. It is applied uniformly over all the radar coverage, without any consideration of the altitude of the ground for each pixel of the radar QPE map. The result is a single radar QPE map corresponding to a horizontal reference level aloft (not at ground level), and for the Moucherotte radar (1910 m a.s.l.) at least $1700 \mathrm{~m}$ above the bottom of the valley, and higher if the melting layer is higher.

- Then by the hourly calibration procedure of each radar QPE, which allows to correct a mean bias of each single radar QPE map before the merging of all the single radar QPE in the composite. This radar-rain gauge adjustment procedure estimates a single hourly calibration factor by radar, constant in space. For the Moucherotte radar QPE, the mean altitude of the rain gauges selected by this calibration procedure in 2016 was equal to $1155 \mathrm{~m}$ a.s.l, with $91 \%$ of the rain gauges selected being installed between $800 \mathrm{~m}$ and $1860 \mathrm{~m}$ a.s.l. In consequence, the mean calibration factors were representative of these altitudes for the Moucherotte radar, and the calibrated single radar QPEs were representative of horizontal reference levels on average corresponding to $1155 \mathrm{~m}$ a.s.l.

These two successive processing thus contribute to estimate radar QPEs representative of horizontal reference levels at mid-altitude. The comparison of annual accumulations of theses radar QPEs (merged 
in PANTHERE) with annual rain gauge measurements, which are impacted by altitudinal gradients of precipitation, leads to the general bias observed: a common overestimation of the radar QPEs at the bottom of the valleys, and a systematic underestimation at the highest altitudes. The next section investigates the altitudinal gradients of precipitation estimates and their variability for different accumulation times for each massif.

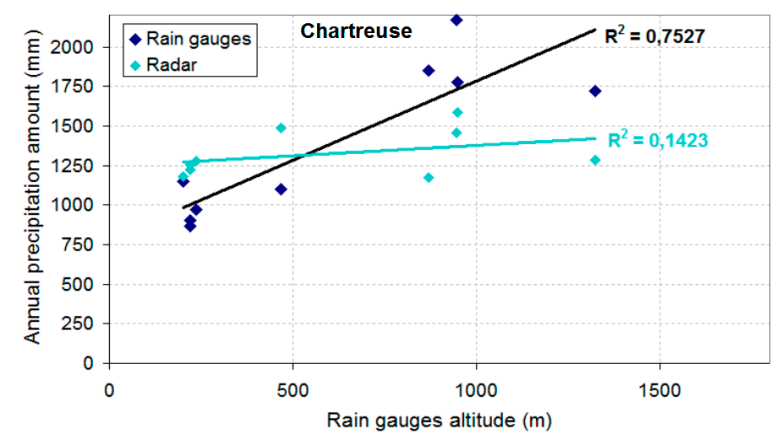

(a)

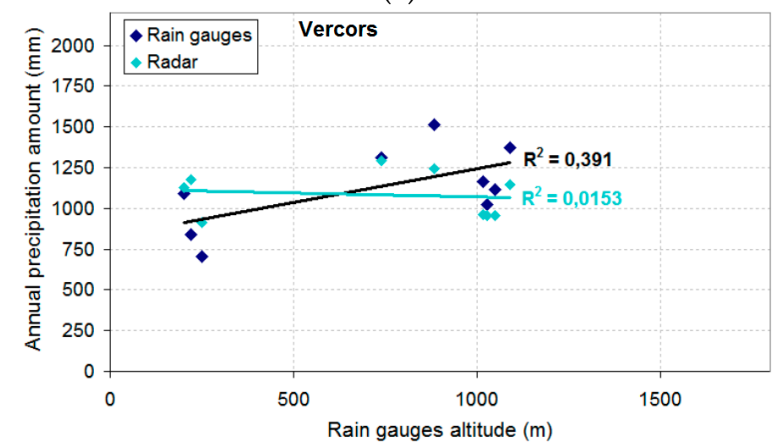

(b)

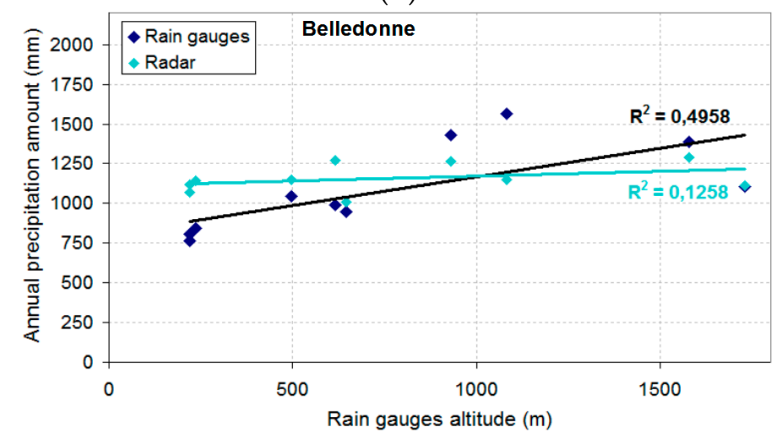

(c)

Figure 4. Comparison of rain gauge annual accumulations and the corresponding radar QPEs in 2016 as a function of rain gauge altitudes, for a subset of nine rain gauges for Chartreuse and Vercors, and ten rain gauges for Belledonne.

\subsection{Comparison of Annual, Seasonal, Monthly, and Daily Altitudinal Gradients of Precipitation}

\subsubsection{Normalization of the Gradient Estimates}

For each massif, estimates of annual, monthly or daily altitudinal gradients of precipitation (in $\mathrm{mm} \mathrm{m}^{-1}$ ) represent the mean increase in $\mathrm{mm}$ of the corresponding precipitation accumulation for an increase of 1 meter in altitude. These values do not have the same meaning for small accumulations of few millimeters as daily precipitation, or accumulations of thousands of millimeters as annual precipitation. Even for the same time scale, these gradient estimates depend on the considered amount of precipitation over a massif (Figure 5). To compare altitudinal gradient estimates for different temporal accumulations, different location or different time periods, it is thus necessary to normalize 
these estimations in order to express the gradients for an identical precipitation amount, equal to $1 \mathrm{~mm}$. The normalized or relative gradients are then expressed in $\mathrm{m}^{-1}$.

For the three massifs, the gradient estimates (in $\mathrm{mm} \mathrm{m}^{-1}$ ) depend linearly on the mean precipitation, or on the maximal precipitation recorded by the rain gauges for the massif (example for Chartreuse in Figure 5). For the three massifs, the correlation is stronger with the maximal precipitation than with the mean precipitation. The maximal precipitation is thought to be more representative of the rain event magnitude for the shortest time periods, and less influenced by the horizontal variability of the precipitation over the massif or by sampling effects due to the limited number of rain gauges non-homogeneously distributed on the relief. For example, four of the nine rain gauges allocated to the Chartreuse massif are located at the bottom of the valleys, which largely impact the mean precipitation estimates. For all these reasons, for this comparison of annual to daily results, we have chosen to normalize each altitudinal gradient estimate with the maximal precipitation amount recorded by the subset of rain gauges for a massif and for the time period considered.

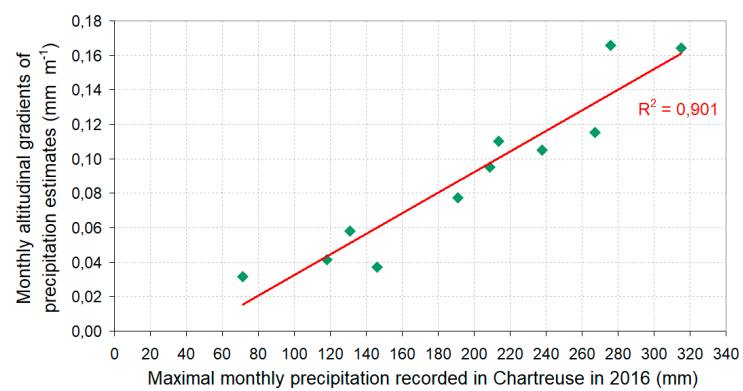

(a)

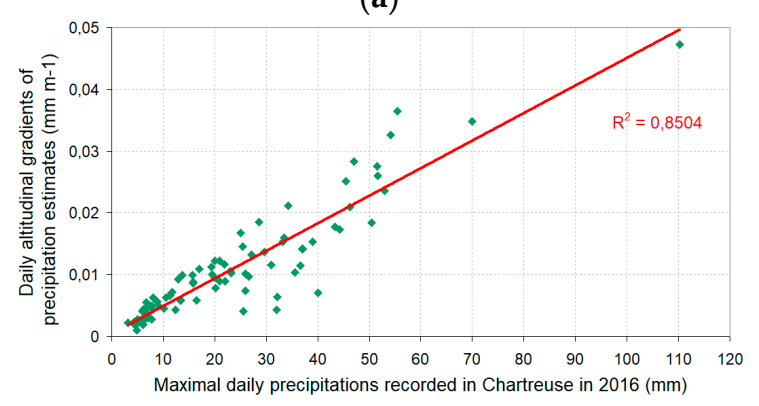

(c)

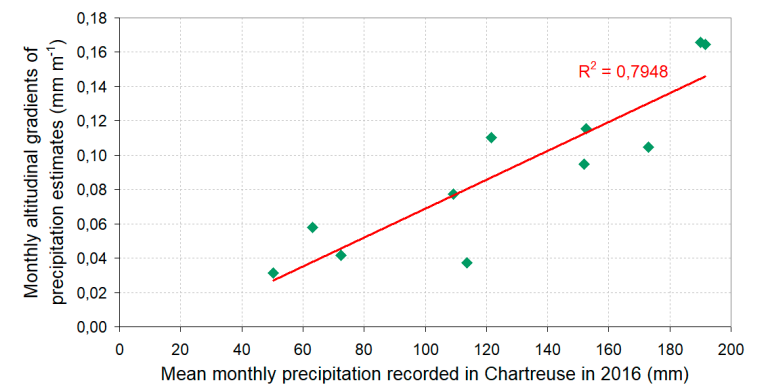

(b)

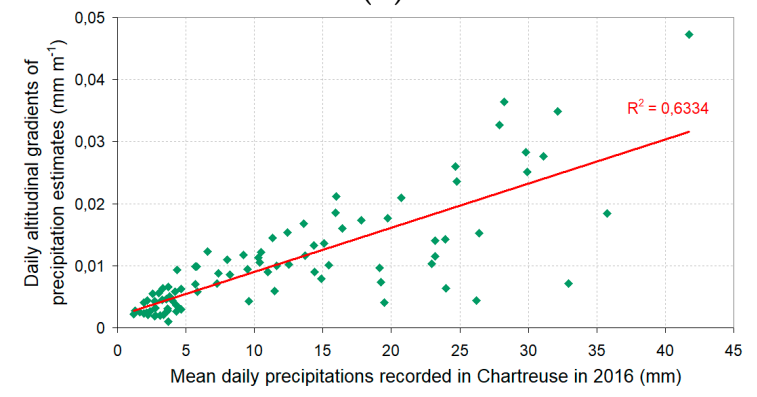

(d)

Figure 5. Relation between altitudinal gradient estimates and magnitude of the precipitation, for the Chartreuse massif. (a) With the maximal monthly precipitation recorded; (b) with the mean monthly precipitation recorded; (c) with the maximal daily precipitation recorded; and (d) with the mean daily precipitation recorded. For daily precipitation, only significant gradients have been used.

\subsubsection{Comparison of the Relative Gradient Estimates for Different Temporal Accumulations}

Table 1 presents the values of the annual and seasonal relative altitudinal gradient estimates for each massif. Figure 6 also presents, on the same picture for each massif, the relative altitudinal gradient estimates for different temporal accumulations, in order to compare the variations of the values estimated at the different time scales. Annual, seasonal, and monthly gradient estimates are presented as a function of the time, the letters of the bottom scale standing for the names of the months. On the same graph, the daily gradient estimates are plotted as a function of the maximal daily precipitation (top scale). Both significant and non-significant daily gradients are presented to show the importance of the non-significant gradients filtering at this time scale.

One can observe that the normalization does not produce the same annual altitudinal gradient value for the three massifs, these gradients depending on factors characteristic of each massif (Chartreuse presenting a stronger gradient than Vercors and Belledonne). But for each massif, the relative gradient values are very consistent for all the temporal accumulations scales (yearly, seasonal, monthly, daily), 
the gradient estimates for shorter durations varying around the annual value. For seasonal or monthly values, it was not possible to identify any common trend for the three massifs. This result is not surprising for a unique year, and in [4] Valéry found that the seasonal variation of the mean altitudinal gradient of precipitation is weak in France in comparison with other countries $\left(2.7 \times 10^{-4} \mathrm{~m}^{-1}\right.$ for the all French territory).

Table 1. Annual and seasonal relative altitudinal gradient estimates (and corresponding $\mathrm{R}^{2}$ values).

\begin{tabular}{ccccc}
\hline $\begin{array}{c}\text { Gradients } \\
\mathbf{( 1 0}^{-\mathbf{4}} \mathbf{~}^{-\mathbf{1}}\end{array}$ & $\begin{array}{c}\text { Chartreuse } \\
\text { (9 Rain Gauges) }\end{array}$ & $\begin{array}{c}\text { Vercors } \\
\text { (9 Rain Gauges) }\end{array}$ & $\begin{array}{c}\text { Belledonne } \\
\text { (10 Rain Gauges) }\end{array}$ & $\begin{array}{c}\text { Belledonne } \\
\text { (9 Rain Gauges) }\end{array}$ \\
\hline annual & $4.6(0.75)$ & $2.7(0.39)$ & $2.3(0.50)$ & $2.2(0.47)$ \\
\hline (D)JF & $5.7(0.85)$ & $2.3(0.43)$ & $1.8(0.27)$ & $1.8(0.26)$ \\
MAM & $4.6(0.66)$ & $2.9(0.33)$ & $2.35(0.59)$ & $2.34(0.59)$ \\
JJA & $4.2(0.78)$ & $1.5(0.12)^{1}$ & $2.9(0.50)$ & $2.9(0.49)$ \\
SON & $3.9(0.72)$ & $3.9(0.66)^{2}$ & $1.0(0.59)^{3}$ & $1.2(0.36)$ \\
\hline
\end{tabular}

In italic, results with reduced significance: ${ }^{1} R^{2}<0.25 .{ }^{2}$ With 18 missing days in October. ${ }^{3}$ No estimates in November.

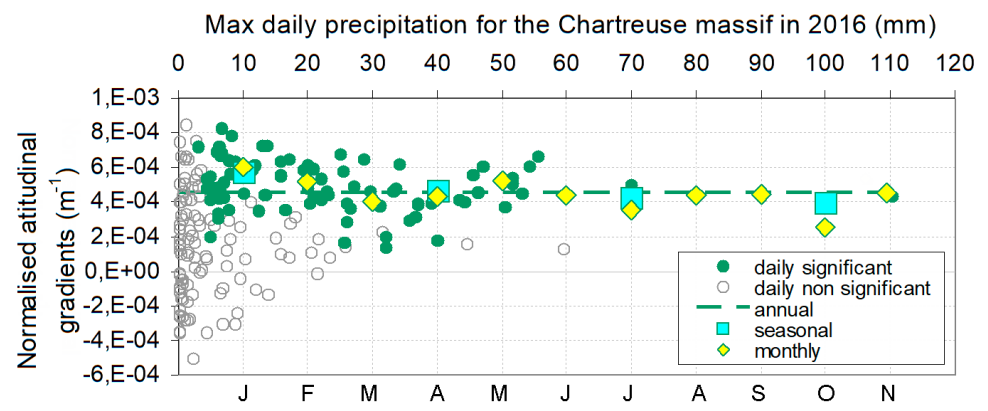

(a)

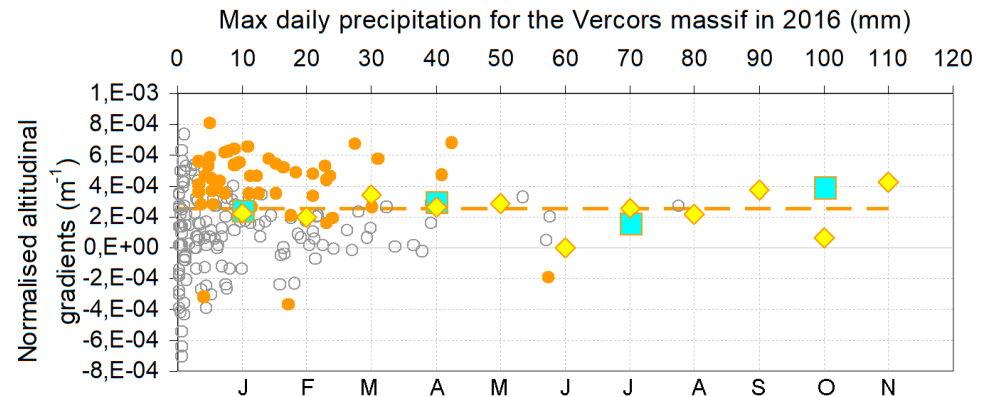

(b)

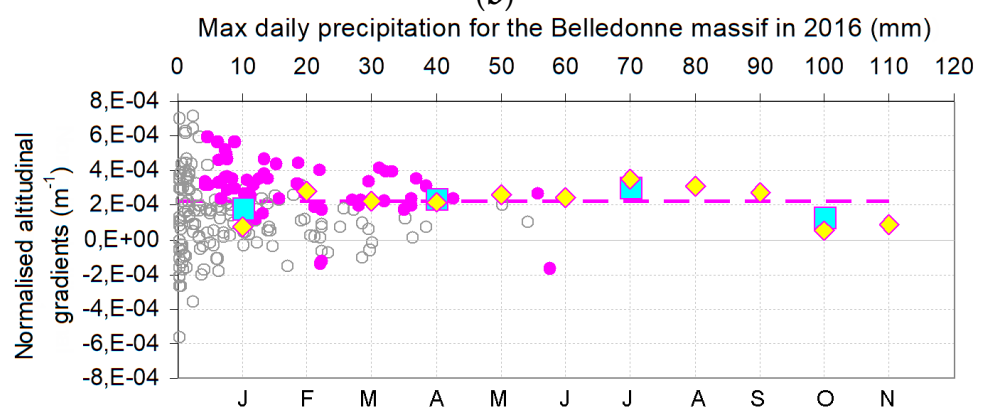

(c)

Figure 6. Comparison of the relative altitudinal gradient estimates for Chartreuse (a), Vercors (b), and Belledonne (c). Colored circles: significant daily gradient estimates as a function of the maximal daily precipitation in $\mathrm{mm}$ (top scale). Non-colored circles: non-significant daily gradient estimates as a function of the maximal daily precipitation. Dashed line: annual gradient estimate. Square and diamond respectively seasonal and monthly gradient estimates as a function of time (bottom scale). For Belledonne, the subset of nine rain gauges is considered in order to have values in November. 
For non-filtered daily accumulations, the variability of gradient estimates is large, but a great part of this variability is due to non-significant gradients estimates, corresponding to weak precipitation on a massif, or corresponding to the absence of observed gradient $\left(R^{2}<0.25\right)$. These absences of observed gradient can be due to the meteorological situation, but also frequently due to the great horizontal variability of the daily precipitation over the small subsets of rain gauges. In this case, the ground level measurements uniquely show the horizontal distribution of precipitation, and it is not possible to estimate an altitudinal gradient of precipitation. The variability of the significant daily altitudinal gradient estimates is more limited, and practically all the estimate values are positive (Table 2). For the Vercors and Belledonne massifs, the few negative gradient values correspond to four days of heavy precipitation (with heavy rain cells for at least two of the days), and one day with small precipitation over all the rain gauges ( 1 to $7 \mathrm{~mm}$ a day). However, on average for the three massifs, $63 \%$ of the days with significant precipitation do not allow to estimate a daily altitudinal gradient of precipitation. Only $37 \%$ of these days produce a determination coefficient value between precipitation and altitude above 0.25 . The percentage of $\mathrm{R}^{2}$ values above 0.25 increases to $76 \%$ for monthly gradients, $92 \%$ for seasonal gradients, and 100\% for annual gradients (on average for the three massifs).

Table 2. Rate of positive or negative daily gradients, in function of the filtering.

\begin{tabular}{|c|c|c|c|c|c|}
\hline \multirow[t]{2}{*}{ Type of Filtering } & $\begin{array}{l}\text { Chartreuse } \\
\text { Gradients }\end{array}$ & \multicolumn{2}{|c|}{$\begin{array}{c}\text { Vercors } \\
\text { Gradients }\end{array}$} & \multicolumn{2}{|c|}{$\begin{array}{c}\text { Belledonne } \\
\text { Gradients }\end{array}$} \\
\hline & $>0<0$ & $>0$ & $<0$ & $>0$ & $<0$ \\
\hline No filtering (i.e., all values) & $69 \% \quad 31 \%$ & $74 \%$ & $26 \%$ & $67 \%$ & $33 \%$ \\
\hline Filtering only weak precipitation & $93 \% \quad 7 \%$ & $84 \%$ & $16 \%$ & $85 \%$ & $15 \%$ \\
\hline Filtering both weak precipitation and absence of gradients & $100 \% \quad 0 \%$ & $94 \%$ & $6 \%$ & $95 \%$ & $5 \%$ \\
\hline
\end{tabular}

\subsection{Vertical Structures of Precipitation Observed by XPORT from the Bottom of the Valleys}

XPORT allows to describe the structure of the precipitation in the atmosphere into the valleys both vertically and horizontally, at altitudes below the measurement altitude for radars of the national network. This is particularly interesting when the melting layer is near or below the altitude of the operational Moucherotte radar, which is common in the winter season.

XPORT measurements, at a 25 degrees elevation angle, were used to estimate mean apparent vertical profiles of precipitation within and below the melting layer, at altitudes close to those of the rain gauges. These vertical profiles were estimated in three different sectors $\left(V_{S}\right.$ profiles, " $\mathrm{s}$ " standing for sector) positioned in direction of the three massifs (north, east, west). However, because of the limited horizontal coverage of the measurement at 25 degrees elevation angle, below $2800 \mathrm{~m}$ a.s.l. these profiles were mainly estimated not over the massifs but in the valleys, within the ring of 4-6 km in range shown in Figure 2. Mean vertical profiles for each complete antenna rotation (all azimuths used) have also been estimated in order to follow the temporal evolution of the vertical structures $\left(\mathrm{VP}_{\mathrm{T}}\right.$ profiles, " $\mathrm{T}$ " standing for temporal). The results showed that the spatial variability of the vertical profiles of precipitation into the valleys widely fluctuates as a function of the weather situation. Figures 7 and 8 present two examples of situations, one with spatially homogeneous precipitation (6 May 2017), and the other with small precipitation cells moving quickly mainly on Vercors, and on western part of Chartreuse and the valleys (22 November 2016). For the first example with spatially homogeneous precipitation, the three $\mathrm{VP}_{\mathrm{S}}$ profiles are very similar. The temporal evolution of the $\mathrm{VP}_{\mathrm{T}}$ profiles, and the AROME estimates of the $0{ }^{\circ} \mathrm{C}$ isotherm altitude, also indicate a marked evolution of the melting layer altitude. The hourly rain gauges confirm the same mean precipitation on all the massifs, and show an increase of precipitation with altitude for Chartreuse and Belledonne massifs (no significant gradient for Vercors with $\mathrm{R}^{2}=0.015$ ). For the second example, with heterogeneous precipitation, the three $\mathrm{VP}_{\mathrm{S}}$ profiles are different both for the intensity of the bright band peak and the gradient below the melting layer. The spatial distribution of the precipitation, mainly in the west part of the area, well explains these differences. The hourly rain gauges indicate an increase of precipitation with altitude for 
Vercors, and no significant gradient for Chartreuse and Belledonne massifs $\left(R^{2}<0.2\right)$, which recorded less than half of the amount of precipitation recorded in Vercors. We can also indicate that the mean $\mathrm{VP}_{\mathrm{T}}$ profile for all this precipitation event is absolutely vertical (i.e., constant) below the melting layer, without any possibility to suspect the horizontal variability revealed by the sector analysis. This great spatial variability makes estimation of vertical gradients very difficult at very short time scales.

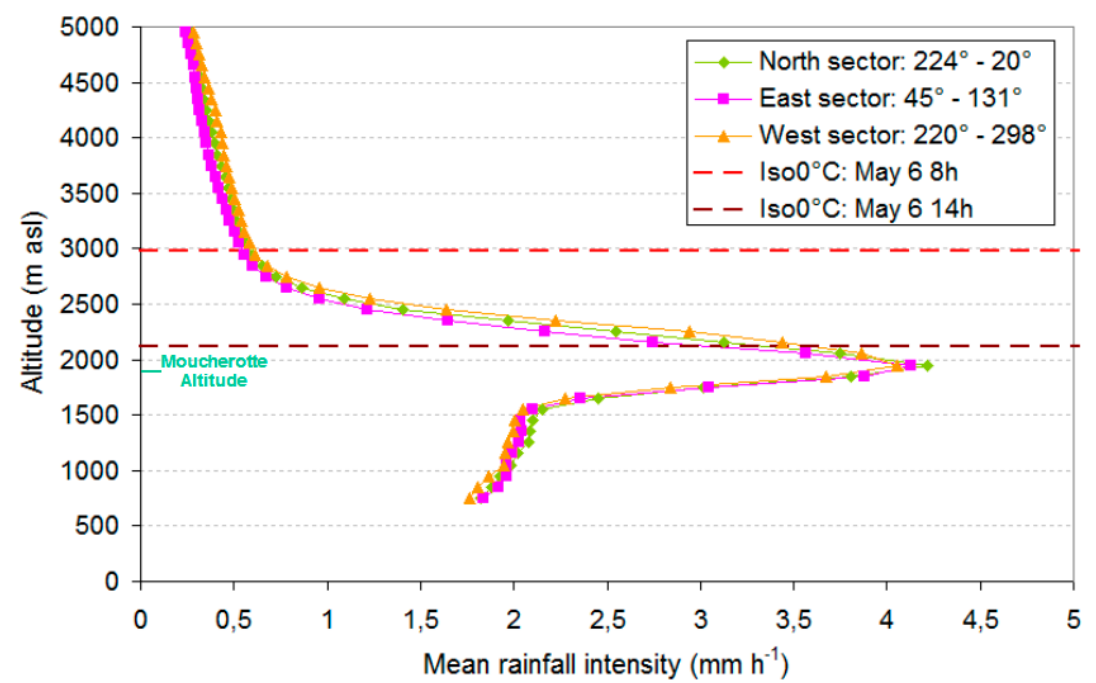

(a)

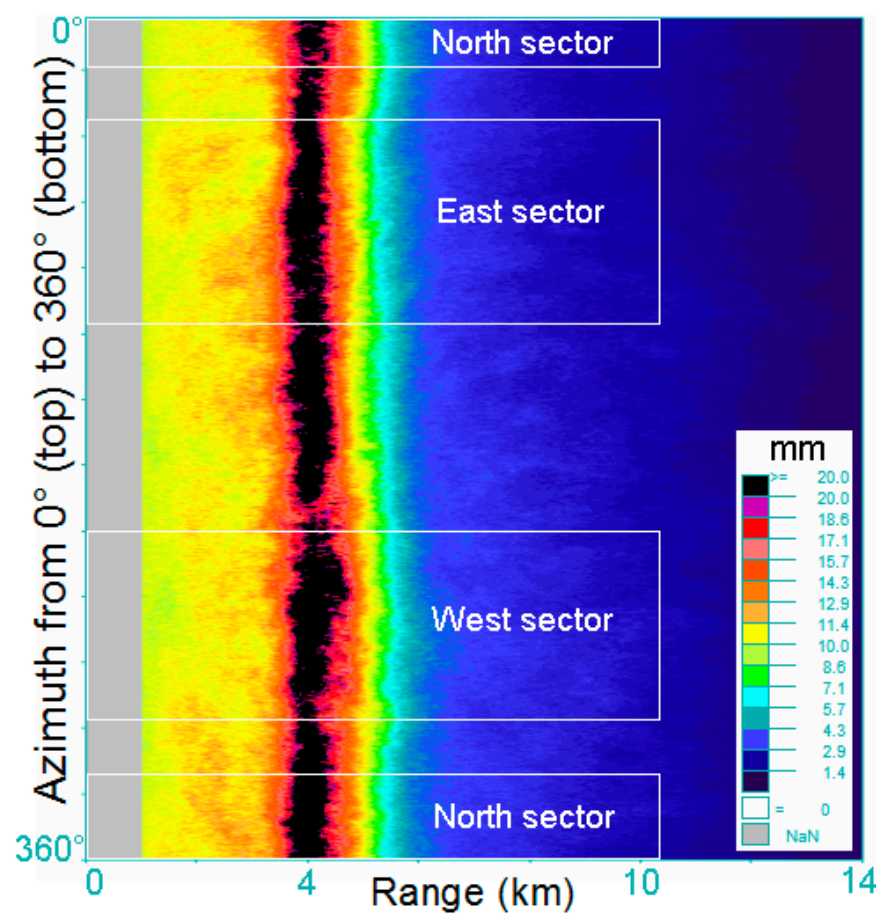

(b)

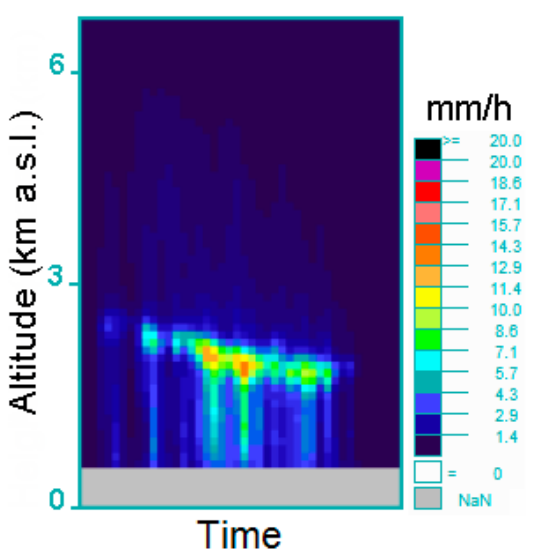

(c)

Figure 7. Example of mean apparent vertical profiles with spatially homogeneous precipitation in the valleys (6 May 2017, from $8 \mathrm{~h}$ to $14 \mathrm{~h}$ UTC). (a) Mean vertical profiles in three sectors (VPS profiles) at $25^{\circ}$ elevation angle. Reflectivity $\mathrm{Z}$ values have been converted in intensities of precipitation $\mathrm{R}$, with the relationship $Z=200 R^{1.6}$. Dashed lines: altitude of $0{ }^{\circ} \mathrm{C}$ isotherm from AROME numerical weather prediction model at the beginning and the end of the considered sequence; (b) total radar precipitation accumulation (in $\mathrm{mm}$ ) by azimuth as a function of range. Data within the first $1.3 \mathrm{~km}$ range is not usable; and (c) $\mathrm{VP}_{\mathrm{T}}$ profiles: temporal evolution of the mean precipitation intensity in $\mathrm{mm} / \mathrm{h}$ (all sectors combined). 


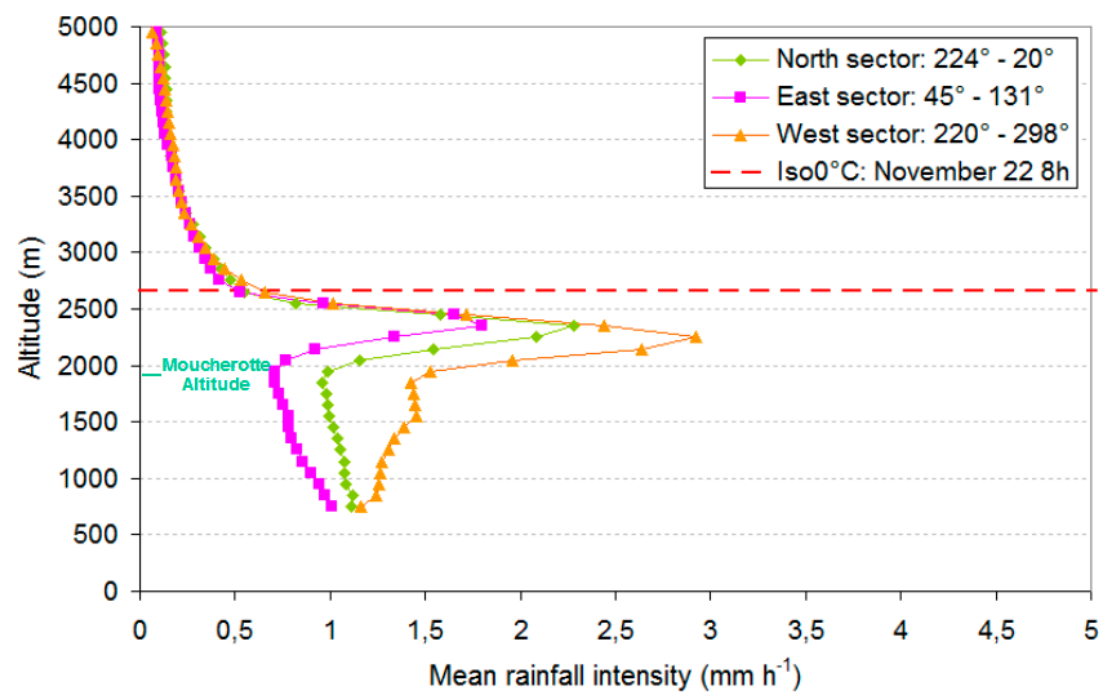

(a)

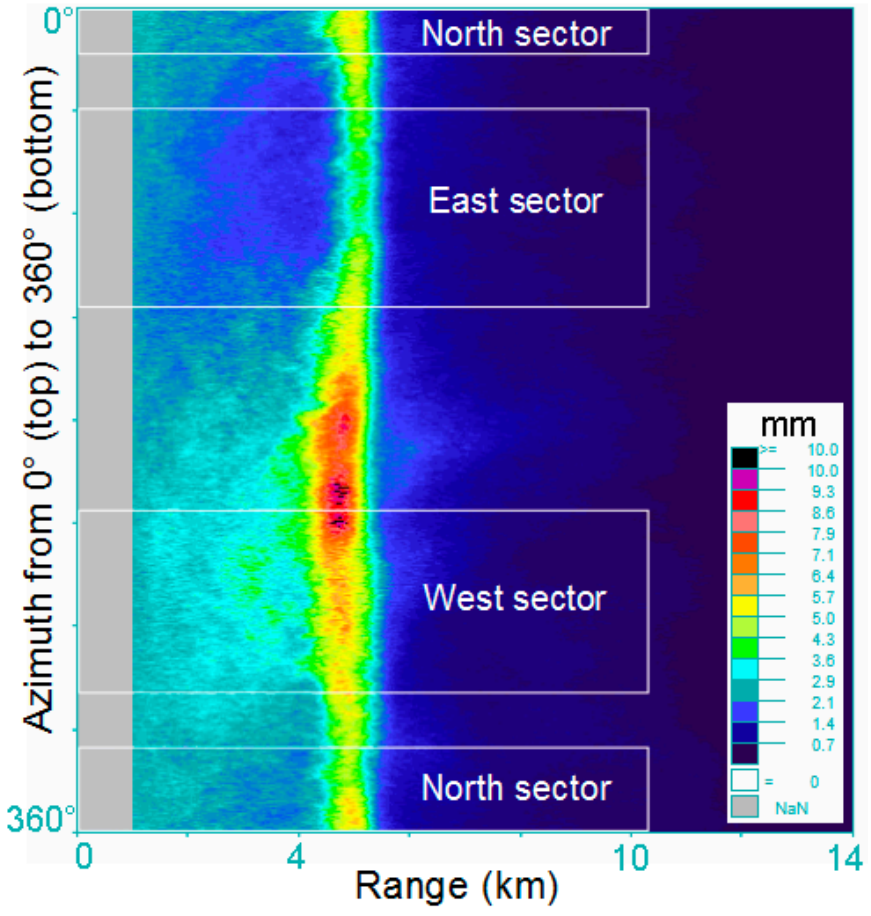

(b)

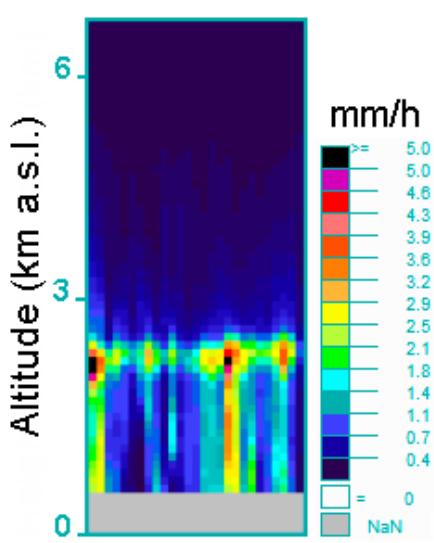

Time

(c)

Figure 8. Example of mean apparent vertical profiles impacted by the spatial repartition of the precipitation in the valleys (22 November 2016, from $7 \mathrm{~h}$ to $9 \mathrm{~h} 20 \mathrm{~min}$ UTC). (a) Mean vertical VP profiles in three sectors at $25^{\circ}$ elevation angle. Reflectivity $\mathrm{Z}$ values have been converted in precipitation intensity $R$, with the relationship $Z=200 \mathrm{R}^{1.6}$. Dashed lines: altitude of $0{ }^{\circ} \mathrm{C}$ isotherm from AROME NWP model; (b) total radar precipitation accumulation (in $\mathrm{mm}$ ) by azimuth as a function of range; and (c) $\mathrm{VP}_{\mathrm{T}}$ profiles: temporal evolution of the mean precipitation intensity in $\mathrm{mm} / \mathrm{h}$ (all sectors combined).

\section{Discussion}

Defining altitudinal gradients of precipitation by valley or massif, or a part of a massif, is not an easy task, the number of rain gauges in mountain being limited, and these gradients depending on many factors. Furthermore, some rain gauges can be influenced by the local context (or recurrent phenomenon) impacting the amount of precipitation recorded. For example in this study, the rain gauge (200 $\mathrm{m}$ a.s.1.) in the north-west valley (which is the gateway to the confluence for the main atmospheric flow) records on average more precipitation than all the other stations at the bottom of the 
valleys. The highest rain gauge (1730 $\mathrm{m}$ a.s.1.) near the extremity of the north-west face of Belledonne, records little precipitation for its altitude. Therefore, measurements of this single rain gauge reduce the correlation between precipitation and altitude for Belledonne. In addition, the western rain gauges on the Vercors plateau record on average more precipitation than the eastern rain gauges at the same altitude. This phenomenon reduces significantly the correlation between precipitation and altitude for the Vercors subset, but the trends are identical in the west and east parts of the massif. Nevertheless, these locally influenced rain gauge measurements do not mask the general trend observed between precipitation and altitude with around ten rain gauges by massif.

For the Chartreuse, Vercors, and Belledonne massifs, the annual altitudinal gradient of precipitation estimates in 2016, were respectively $4.6 \times 10^{-4} \mathrm{~m}^{-1}, 2.7 \times 10^{-4} \mathrm{~m}^{-1}$, and $2.3 \times 10^{-4} \mathrm{~m}^{-1}$ relatively to the maximal precipitation on the massif, and $7.2 \times 10^{-4} \mathrm{~m}^{-1}, 3.7 \times 10^{-4} \mathrm{~m}^{-1}$, and $3.3 \times 10^{-4} \mathrm{~m}^{-1}$ relatively to the mean precipitation on the massif. The comparison of these values with other studies is not easy when these studies estimate climatological values of vertical gradients or vertical rainfall profiles over decades. The comparison is also difficult when the studies present results at the scale of the entire mountain chain (or entire countries), and for some studies by sampling only few hydrological alpine basins. Another main difficulty appears when the gradient values were not normalized, the values expressed in $\mathrm{mm} \mathrm{m}^{-1}$ depending greatly on the amount of precipitation considered. With all these reservations, it is possible to mention that Valéry in [4] found $3.7 \times 10^{-4} \mathrm{~m}^{-1}$ for the 1995-2005 period and for the entire French Alps (247 ground stations). It is not possible to directly compare our results to the SAFRAN vertical profiles of climatological precipitation (in $\mathrm{mm}$ ) computed for seven different weather regimes. Nevertheless, it is possible to indicate that these profiles correspond to vertical gradient strictly positive from $300 \mathrm{~m}$ to $1800 \mathrm{~m}$ a.s.l. similar to the results in Table 1. For Vercors and Belledonne, the SAFRAN profiles indicate that the vertical gradients of precipitation decrease slowly and regularly as altitude increases, which is not inconsistent with the assumption of a constant gradient particularly for Vercors. For Chartreuse, the SAFRAN profiles show a discontinuity, with at $300 \mathrm{~m}$ a.s.l. a strong gradient greatly decreasing until around $900 \mathrm{~m}$ a.s.l., and above $900 \mathrm{~m}$ a.s.l. a weak gradient rather constant until $1800 \mathrm{~m}$ a.s.l. This feature could explain the strong gradient estimated for Chartreuse in this study, with only one rain gauge above $950 \mathrm{~m}$ a.s.l.

An important question is the relation between the altitudinal precipitation gradients observed at ground level by rain gauges, and the vertical profiles of precipitation detected by radar in the atmosphere. As explained, rain gauge measurements were not directly comparable to the XPORT measurements, because they have been recorded in the same direction but at greater distance from the radar, and on the massifs, not into the valleys. Besides, for the short duration of the XPORT records, only a few hourly rain gauges can be used (with only two rain gauges above $1050 \mathrm{~m}$ a.s.l.). This attempt to compare rain gauge measurements at ground level and mean apparent vertical radar profiles however provides some understanding of the difficulties in estimating altitudinal gradients of precipitation for very short durations (few hours): the number of hourly rain gauges available is too small to robustly estimate altitudinal gradients, and the great spatial variability masks a great part of the altitudinal gradients of precipitation. Even when the precipitation was relatively spatially homogeneous, it has been very difficult to estimate simultaneously altitudinal gradients of precipitation for all the three massifs (only two massifs for the example on Figure 7). This difficulty disappears for longer temporal accumulations (monthly, seasonal, annual periods).

This study did not consider the possibility of precipitation underestimation at high altitude due to difficulties of rain gauge measurement, and no specific correction was applied in this study on data provided by the Météo-France national databases (the data validation and correction being performed by the databases administrators). However, if the rain gauge data underestimated the true precipitation amounts at high altitude, then the gradient values were also underestimated, as well as the radar QPE bias, these QPE clearly underestimating the precipitation in altitude. 


\section{Conclusions}

These results suggest some responses to the questions at the origin of this study, and first how the altitudinal gradients of precipitation could explain the radar QPE bias observed. For the three massifs surrounding the Grenoble conurbation, the results of the annual, seasonal and monthly analysis, confirmed the difference between radar QPE and rain gauge measurements: a precipitation amount at ground level increasing with the altitude of the gauges between $200 \mathrm{~m}$ and $1730 \mathrm{~m}$ a.s.l., and a relatively constant radar QPE at all altitudes. This difference explains the general bias observed in the three massifs and valleys between radar and rain gauge estimates, with a general tendency for the PANTHERE radar QPE to overestimate precipitation at low altitude, and underestimate at high altitude. The parts of the radar data processing which could influence the value of this radar QPE bias was also pointed out: the VPR processing which bring the radar measurements down to a horizontal reference level at the altitude of the radar or of the bottom of the melting layer, and the uniform calibration of the single radar QPEs by hourly rain gauge data, which shift this reference level to the mean altitude of the rain gauges used. These results confirm the interest of works in progress supported by Météo-France and IGE to bring information on VPR below the altitude of measurement of the current radars in mountain, for example by integrating radar measurements from the bottom of a valley, or by using 3D analysis of the AROME NWP model at all altitudes [20]. Calibration procedures using rain gauges measurements and varying in space could also be interesting when the precipitation fields are not independent from the relief, or when these fields depend on local bias [21].

Concerning the second question, the analysis has shown difficulties to estimate altitudinal gradients of precipitation at the daily time scale. This is probably due to the limited number of rain gauges, and to phenomena impacting the precipitation amount recorded by rain gauges, and possibly with a higher impact than the altitudinal gradients of precipitation. In this study, we observed the impact of the weather situation (particularly weak precipitation), and of the horizontal variability of daily precipitation fields. This horizontal variability can mask a possible altitudinal gradient of precipitation, and then the ground level measurements uniquely show the spatial distribution of precipitation. Precipitation accumulation over larger time steps reduces the horizontal variability of the precipitation fields, the impact of weak precipitations, and probably the impact of other variable phenomena on the precipitation amount recorded by the rain gauges, which facilitates the estimation of altitudinal gradients of precipitation. In 2016, monthly, seasonal, and annual precipitations systematically revealed a positive altitudinal gradient of precipitation for the three massifs, when the correlation between precipitation and altitude was significant. Furthermore, the variability of the relative gradient estimates around the annual value decreased as the time scale increased. The proportion of significant correlation $\left(R^{2}>0.25\right)$ increased with the time scale from $76 \%$ for monthly precipitation to $92 \%$ for seasonal precipitation and $100 \%$ for annual precipitation (on average for the three massifs). However, it is difficult with these results to infer some relevant relationship between the relative altitudinal gradients of precipitation observed at the different time scales.

The utilization of XPORT research radar data, acquired from the bottom of the confluence of the valleys, has also been the occasion to use few hours of accumulation. The XPORT vertical profiles estimated in three different angular sectors confirmed the possibility of wide horizontal variability of the precipitation in few kilometers, even within a valley. This sub-daily spatial variability contributes to the difficulties to estimate altitudinal gradients of precipitation at the daily time scale, and to the variability of these difficulties from a massif to another. Future works would be necessary to better analyze the relation between altitudinal gradients of precipitation observed with rain gauges at ground level, and vertical profiles of precipitation detected in the atmosphere by radar (third question). For this, a new measurement campaign with XPORT should provide new data to investigate the 3D structure of precipitation in the valley. This is an interesting topic to determine the need and possibility of considering these altitudinal gradients of precipitation into the radar data processing, in order to improve the quality of radar QPE in mountains. 
These results have been obtained for three neighboring massifs in the north-western part of the French Alps for the year 2016. We can indicate that similar annual altitudinal gradients of precipitation have been observed in 2017 for theses three massifs. The previous results obtained with 430 rain gauges in all the French Alps in 2016 described in [1], and summarized in Figure 1, suggest that these new results could explain the bias between radar QPE and rain gauge measurements for a great part of the mountain range in France. Therefore, the general bias of the PANTHERE radar QPE with altitude, affecting the correct estimation of the precipitation amount on the massifs at all altitudes and the accurate determination of the snowpack, could widely impact hydrology, nivology, and prevention of natural hazards. This issue could also concern other weather radar data processing systems, which could be affected by the same effect.

Author Contributions: Methodology, D.F.; Formal analysis, D.F.; Resources, G.D. for XPORT data; Writing-Original Draft Preparation, D.F.; Writing-Review \& Editing, D.F., G.D. and N.G.; Project Administration, N.G. for Météo-France, G.D. for IGE.

Funding: This research received no external funding.

Acknowledgments: This work benefits from the collaboration and exchanges between the CMR team of Météo-France and the researchers of the HMCIS team of IGE. It also benefits from exchanges with researchers of the French Snow Research Center, a research unit of the CNRM (Centre National de Recherches Météorologiques): special thanks to Fatima Karbou, Camille Birman, and Laurent Merindol. This study also greatly benefits from the EDF rain gauges network.

Conflicts of Interest: The authors declare no conflict of interest.

\section{References}

1. Faure, D.; Gaussiat, N.; Dupuy, P.; Delrieu, G.; Yu, N.; Sarter, F. Quality analysis of the 2016 quantitative precipitation estimates in the French Alps. In Proceedings of the 38th Conference on Radar Meteorology, Chicago, IL, USA, 31 August 2017.

2. Durand, Y.; Brun, E.; Mérindol, L.; Guyomarc'h, G.; Lesaffre, B.; Martin, E. A meteorological estimation of relevant parameters for snow models. Ann. Glaciol. 1993, 18, 65-71. [CrossRef]

3. Sevruk, B. Regional dependency of precipitation-altitude relationship in the Swiss Alps. Clim. Chang. 1997, 36, 355-369. [CrossRef]

4. Valéry, A. Modélisation Précipitations-Débit Sous Influence Nivale. Élaboration d'un Module Neige et Évaluation sur 380 Bassins Versants. Ph.D. Thesis, Institut des Sciences et Industries du Vivant et de l'Environnement (AgroParisTech), Paris, France, February 2010.

5. Durand, Y.; Laternser, M.; Giraud, G.; Etchevers, P.; Lesaffre, B.; Mérindol, L. Reanalysis of 44 yr of climate in the French Alps (1958-2002): Methodology, model validation, climatology, and trends for air temperature and precipitation. J. Appl. Meteorol. Climatol. 2009, 48, 429-449. [CrossRef]

6. Desurosne, I. Gradients D'intensités de Pluie en Zones à Relief: Expérimentations et Premières Modélisations des Données d'un Réseau Rhônalpin, le TPG. Ph.D. Thesis, Université Louis Pasteur Strasbourg-I, Strasbourg, France, September 1992.

7. Desurosne, I.; Oberlin, G.; Blanchet, G. Towards a better knowledge of high basin rainfall fields at small time and space steps: Analysis of rainfall data from an unidirectional northern pre-Alps network. In FRIEND: Fow Regimes of International Experimental and Network Data, Proceedings of the Braunschweig FRIEND Conference, Brunswick, Germany, 11-15 October 1993; Seuna, P., Gustard, A., Arnell, N.W., Cole, G.A., Eds.; IAHS Press: Wallingford, , UK, 1993.

8. Vetter, J. Contribution d'un Code de Calcul Météorologique Méso-échelle à la Climatologie des Pluies en zone de Relief. Ph.D. Thesis, Institut National Polytechnique de Grenoble, Grenoble, France, July 2004.

9. Bénichou, P.; Le Breton, O. Prise en compte de la topographie pour la cartographie des champs pluviométriques statistiques. La Météorologie 1987, 19, 23-34.

10. Canellas, C.; Gibelin, A.L.; Lassègues, P.; Kerdoncuff, M.; Dandin, P.; Simon, P. Les normales climatiques spatialisées Aurelhy 1981-2010: Températures et précipitations. La Météorologie 2014, 85, 47-55. [CrossRef] 
11. Birman, C.; Karbou, F.; Mahfouf, J.; Lafaysse, M.; Durand, Y.; Giraud, G.; Mérindol, L.; Hermozo, L. Precipitation analysis over the French Alps using a variational approach and study of potential added value of ground based radar observations. J. Hydrometeorol. 2017, 18, 1425-1451. [CrossRef]

12. Sevruk, B. Reliability of Precipitation Gradient Estimates. In Proceedings of the XIV International Conference on Carpathian Meteorology, Sofia, Bulgaria, 25-30 September 1989.

13. Blanchet, J.; Marty, C.; Lehning, M. Extreme value statistics of snowfall in the Swiss Alpine region. Water Resour. Res. 2009, 45, W05424. [CrossRef]

14. Grünewald, T.; Lehning, M. Altitudinal dependency of snow amounts in two small alpine catchments: Can catchment-wide snow amounts be estimated via single snow or precipitation stations? Ann. Glaciol. 2011, 52, 153-158.

15. Barry, R.G. Recent advances in mountain climate research. Theor. Appl. Climatol. 2012, 110, 549-553. [CrossRef]

16. Delrieu, G.; Cazenave, F.; Yu, N.; Faure, D.; Boudevillain, B.; Khanal, A.; Augros, C.; Le Bastard, N.; Gaussiat, N. Radar remote sensing for rain/snow estimation in an Alpine context: The Grenoble experiment. In Proceedings of the 10th European Conference on Radar in Meteorology and Hydrology (ERAD 2018), Ede-Wageningen, The Netherlands, 1-6 July 2018.

17. Tabary, P.; Augros, C.; Champeaux, J.L.; Chèze, J.L.; Faure, D.; Idziorek, D.; Lorandel, R.; Urban, B.; Vogt, V. Le réseau et les produits radars de Météo France. La Météorologie 2013, 83, 15-27. [CrossRef]

18. Schaefli, B.; Hingray, B.; Niggli, M.; Musy, A. A conceptual glacio-hydrological model for high mountainous catchments. Hydrol. Earth Syst. Sci. Discuss. 2005, 9, 95-109. [CrossRef]

19. Johansson, B. Areal precipitation and temperature in the Swedish Mountains-An evaluation from a hydrological perspective. Nord. Hydrol. 2000, 31, 207-228. [CrossRef]

20. Le Bastard, T.; Caumont, O.; Gaussiat, N.; Karbou, F. Combined use of volume radar observations and high-resolution numerical weather predictions to estimate precipitation at the ground: Methodology and proof of concept. Atmos. Meas. Tech. Discuss. 2019, under review. Available online: https: //www.atmos-meas-tech-discuss.net/amt-2019-166/ (accessed on 10 May 2019). [CrossRef]

21. Germann, U.; Galli, G.; Boscacci, M.; Bolliger, M. Radar precipitation measurement in a mountainous region. Q. J. R. Meteorol. Soc. 2006, 132, 1669-1692. [CrossRef] 